\title{
Voxel inversion of airborne electromagnetic data for improved groundwater model construction and prediction accuracy
}

\author{
Nikolaj Kruse Christensen ${ }^{1}$, Ty Paul A. Ferre ${ }^{2}$, Gianluca Fiandaca ${ }^{1}$, and Steen Christensen ${ }^{1}$ \\ ${ }^{1}$ Department of Geoscience, Aarhus University, Aarhus, Denmark \\ ${ }^{2}$ Department of Hydrology and Water Resources, University of Arizona, Tucson, USA
}

Correspondence to: Nikolaj Kruse Christensen (nkc07@phys.au.dk)

Received: 18 May 2016 - Discussion started: 15 June 2016

Revised: 5 January 2017 - Accepted: 29 January 2017 - Published: 2 March 2017

\begin{abstract}
We present a workflow for efficient construction and calibration of large-scale groundwater models that includes the integration of airborne electromagnetic (AEM) data and hydrological data. In the first step, the AEM data are inverted to form a 3-D geophysical model. In the second step, the 3-D geophysical model is translated, using a spatially dependent petrophysical relationship, to form a 3-D hydraulic conductivity distribution. The geophysical models and the hydrological data are used to estimate spatially distributed petrophysical shape factors. The shape factors primarily work as translators between resistivity and hydraulic conductivity, but they can also compensate for structural defects in the geophysical model.

The method is demonstrated for a synthetic case study with sharp transitions among various types of deposits. Besides demonstrating the methodology, we demonstrate the importance of using geophysical regularization constraints that conform well to the depositional environment. This is done by inverting the AEM data using either smoothness (smooth) constraints or minimum gradient support (sharp) constraints, where the use of sharp constraints conforms best to the environment. The dependency on AEM data quality is also tested by inverting the geophysical model using data corrupted with four different levels of background noise. Subsequently, the geophysical models are used to construct competing groundwater models for which the shape factors are calibrated. The performance of each groundwater model is tested with respect to four types of prediction that are beyond the calibration base: a pumping well's recharge area and groundwater age, respectively, are predicted by applying the same stress as for the hydrologic model calibration; and
\end{abstract}

head and stream discharge are predicted for a different stress situation.

As expected, in this case the predictive capability of a groundwater model is better when it is based on a sharp geophysical model instead of a smoothness constraint. This is true for predictions of recharge area, head change, and stream discharge, while we find no improvement for prediction of groundwater age. Furthermore, we show that the model prediction accuracy improves with AEM data quality for predictions of recharge area, head change, and stream discharge, while there appears to be no accuracy improvement for the prediction of groundwater age.

\section{Introduction}

Large-scale geological and groundwater models are used extensively to support aquifer management. (Here "large-scale" refers to an area of tens to thousands of square kilometers.) Determining the distribution of hydraulic properties and the geometry and connectivity of the groundwater system is of significant importance because these features control the flow paths (Desbarats and Srivastava, 1991; Fogg et al., 1999; Weissmann and Fogg, 1999). Incorrect reconstruction of the geological structures has thus been recognized as an important source of uncertainty when a groundwater model is used to make predictions outside its calibration base (Refsgaard et al., 2012; Seifert et al., 2012; Zhou et al., 2014). The data traditionally used for structural mapping include lithological logs from boreholes, hydrological data, and hydraulic testing results, but these data are often sparse and unevenly distributed within an investigated do- 
main. In these (very common) cases, data scarcity becomes a major obstacle for structural mapping in relation to largescale groundwater modeling (Refsgaard et al., 2012; Zhou et al., 2014).

Ground-based and airborne electromagnetic methods have shown great potential for mapping geological structures (Jørgensen et al., 2003; Thomsen et al., 2004; Abraham et al., 2012; Oldenborger et al., 2013; He et al., 2014; Munday et al., 2015). For large-scale mapping, the airborne electromagnetic method (AEM) is efficient and cost-effective, supplementing traditional data with dense estimates of electrical resistivity which, in some environments, inform about the lithology and thereby about the structure (Robinson et al., 2008; Binley et al., 2015). AEM measurements can be made quickly over large areas, and the resolution can be as fine as $25 \mathrm{~m}$ in the horizontal direction and $5 \mathrm{~m}$ in the vertical (Schamper et al., 2014), with a penetration depth of up to several hundred meters (Siemon et al., 2009).

Various methods to incorporate resistivity estimates (hereafter referred to as resistivity models) into groundwater model construction have been reported. Manual and knowledge-driven approaches have been used to combine geological, hydrological, and geophysical data with expert knowledge (Jørgensen et al., 2013). However, the manual approach is subjective and can be very time consuming and expensive to use when resistivity models from large AEM surveys are to be incorporated into model construction. Alternatively, more objective and cost-efficient geostatistical modeling approaches (Carle and Fogg, 1996; Deutsch and Journel, 1998; Strebelle, 2002) are available for generating models from a combination of borehole information and AEMdetermined resistivity models. For example: He et al. (2014) used a transition probability indicator simulation approach (Carle and Fogg, 1996), while Gunnink and Siemon (2015) used sequential indicator simulation (Deutsch, 2006). Marker et al. (2015) used a deterministic strategy for the integration of AEM resistivity models into the hydrological modeling process.

The studies just mentioned all used sequential hydrogeophysical inversion approaches (SHI, as defined by Ferré et al., 2009). In SHI the geophysical data are inverted first and independently from the later inversion of the hydrological data. For large-scale groundwater modeling, Herckenrath et al. (2013) and Christensen et al. (2016) used both SHI and joint hydrogeophysical inversion approaches (JHI; as defined by Ferré et al., 2009). In JHI, the geophysical and hydrological data are inverted jointly by linking the geophysical and hydrological models directly through some of their parameters. The linking can, for example, be done by using an Archie's law inspired petrophysical relationship (Archie, 1942) to translate between the geophysical and hydrologic parameters.

In general, petrophysical relationships are difficult to establish because such translation tends to be site-, scale- and facies-specific (Chen et al., 2001; Hyndman and Tronicke,
2005; Slater, 2007) and uncertain (Mazáč et al., 1985; Slater, 2007). The studies by Herckenrath et al. (2013) and Christensen et al. (2016) used a fixed petrophysical relationship throughout the model domain. Better results can be obtained by using a spatially variable relationship, which allows for local translation between hydraulic conductivity and electrical resistivity, and by including the spatially dependent petrophysical parameters in the optimization process (Linde et al., 2006).

There are two other challenges for incorporating resistivity models into large-scale groundwater modeling: differences in model discretization and choice of geophysical regularization methodology. Groundwater models are often discretized in a regular voxel grid, while the traditional resistivity models are 1-D and placed at the respective sounding location. For airborne surveys, for example, the resistivity models are normally located along the flight lines (Christiansen et al., 2006). Such resistivity models therefore need to be relocated to conform to the grid of the groundwater model. The relocation will often be a subtle process where information can be lost. To address this issue, Fiandaca et al. (2015) presented a geophysical modeling approach referred to as "voxel inversion", which decouples the geophysical inversion model space from the geophysical measurement positions. This allows estimation of a 3-D geophysical model that is discretized on the same voxel grid as the groundwater model.

Traditionally, geophysical regularization includes horizontal and vertical smoothing constraints (Constable et al., 1987) or is limited to a few-layer inversion (Auken and Christiansen, 2004), whereas a groundwater system often has sharp-layer or body boundaries. It has therefore been recognized, e.g., by Day-Lewis (2005) and others, that the regularization used to stabilize the geophysical inversion may not reflect the actual hydrologic conditions unless it is chosen carefully. If, for example, smooth regularization is used to estimate resistivity models in a sharply layered system, it will produce a blurred resistivity distribution from which one should be careful with inferring the spatial distribution of hydraulic conductivity to be used in a groundwater model. In this case, it would be better to use minimum gradient support regularization (Portniaguine and Zhdanov, 1999; Blaschek et al., 2008; Vignoli et al., 2015) for the geophysical inversion because the estimated resistivity distribution will tend to consist of fewer, more sharply defined layer boundaries (vertically and horizontally). However, it is often ignored that geophysical data can be inverted using alternative regularization schemes, and to test whether the alternative geophysical models affect the predictive capability of a groundwater model.

The main objective of the present study is to present a novel sequential hydrogeophysical approach whereby a voxel-based 3-D resistivity model is used to parameterize and calibrate a groundwater model. The model parameterization methodology allows the calibration to compensate for errors in the resistivity model. Furthermore, we will demonstrate 


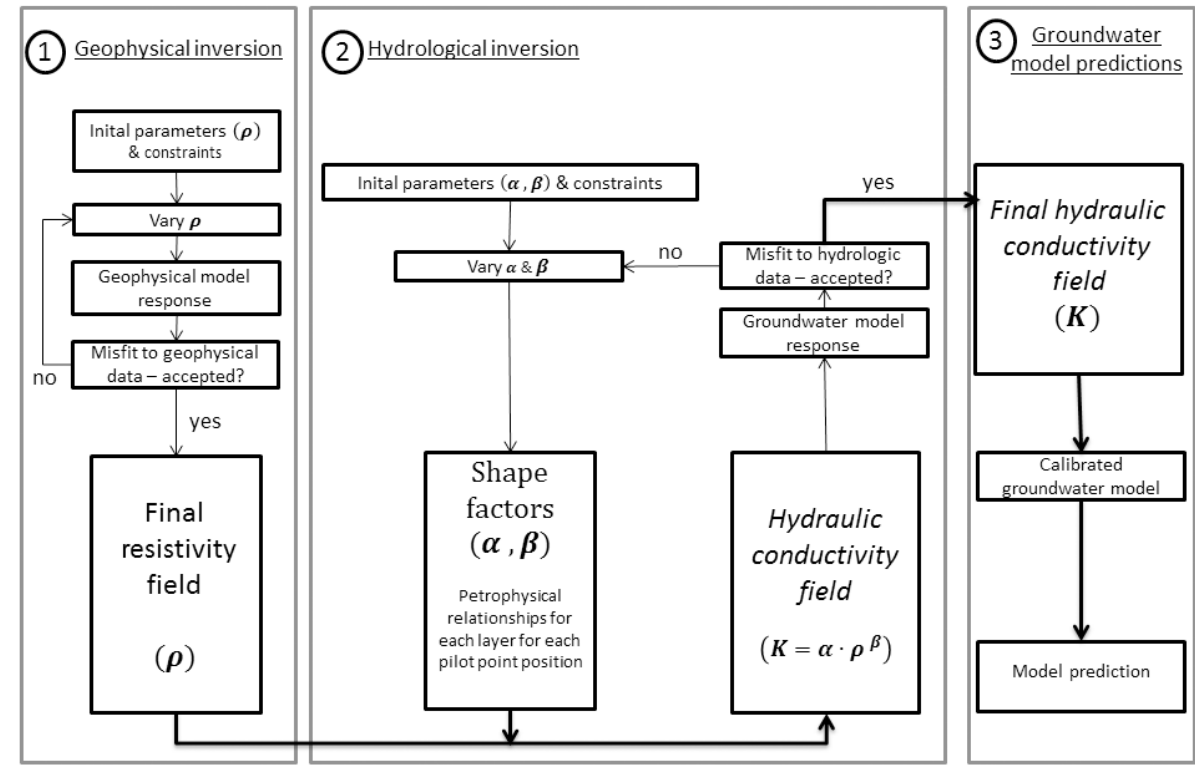

Figure 1. Conceptual flowchart for the sequential hydrogeophysical inversion. First step (box 1): geophysical inversion. Second step (box 2): groundwater model calibration where shape factors of the petrophysical relationship are estimated using hydrological data. Third step (box 3): the calibrated groundwater model is used for predictive modeling.

that it is important for groundwater flow simulations that the underlying resistivity model is estimated using regularization constraints that conform well to the geological environment. Finally, we analyze how groundwater model prediction accuracy depends on the quality of the geophysical data that were used to estimate the resistivity model. Section 2 of the paper presents the methodology. Section 3 describes the synthetic test case used for our demonstration purposes. Section 4 presents the results, while Sects. 5 and 6 present discussions and conclusions of the work, respectively.

\section{Methodology}

Conceptually, we define a translator function that describes the petrophysical relationship between electrical resistivity and hydraulic conductivity. The petrophysical relationship can vary horizontally and vertically, thereby adapting to the local conditions in translation from the geophysical model space to the hydrological model space. Through inversion, the 3-D spatially dependent optimal parameters of the petrophysical relationship are estimated for each layer interval, thereby covering the entire 3-D model space.

Figure 1 provides a workflow for the method. First, the gathered airborne electromagnetic (AEM) data from the survey area are inverted with smooth or sharp horizontal and vertical constraints (Vignoli et al., 2015). This is done by using a recently developed voxel inversion scheme which decouples the geophysical model from the position of the acquired data (Fiandaca et al., 2015). The geophysical model space thus corresponds to the full 3-D hydrological model grid. Secondly, the geophysical voxel-based resistivity model is used as input for the sequential hydrological inversion. The geophysical model parameter (resistivity) is linked to the main investigated parameter (hydraulic conductivity) through a petrophysical relationship that has unknown shape factor values. The shape factor values are estimated through a hydrological inversion which minimizes an objective function describing the misfit between simulated groundwater model responses and corresponding observed hydrological data. Finally, the calibrated groundwater model can be used to make a set of relevant hydrologic predictions. The various steps of the methodology are explained in more detail in the following.

\subsection{Geophysical voxel inversion}

In the first step (Fig. 1, box 1), the AEM data undergo constrained deterministic inversion using recently developed voxel inversion approaches. This approach allows the geophysical model spaces to be spatially decoupled from the geophysical measurement positions (Fiandaca et al., 2015). In most inversion schemes, the forward and inverse formulations use the same model discretization. In the voxel formulation, the two model discretizations are decoupled. The voxel model space thus defines the geophysical properties on the nodes of a regular 3-D grid.

For calculating the forward responses, a "virtual" 1-D model is built at each sounding position. The "virtual" 1D model is defined by a number of layers, and layer thicknesses. The geophysical properties are interpolated from the voxel model space into the layer centers of the virtual model 
that is subsequently used to simulate the forward response for the corresponding sounding.

The voxel inversion approach thus allows for inversion of AEM data into a geophysical model defined on a 3-D regular grid, regardless of the sounding positions. As a result, the geophysical inversion can be conducted using the same grid as that defined for a 3-D groundwater model, thereby minimizing scaling issues in the coupling of geophysical and hydrological models.

The general solution to the non-linear geophysical inversion problem can be found in Auken et al. (2014). To stabilize the inverse problem, either of two types of regularization methods can be applied. The first regularization method is commonly referred to as smoothness-constrained inversion (Constable et al., 1987). The smoothness-constrained inversion tends to reduce contrasts and the resulting geophysical model may appear blurred. The reason for this is found in its minimum-structure L2 norm inversion formalism (Constable et al., 1987; Menke, 2012). Following the notation used by Vignoli et al. (2015), this can be expressed as

$\left(m_{i}-m_{j}\right)^{2} / \sigma_{i, j}^{2}$,

where $m_{i}$ and $m_{j}$ are the constrained parameters and $\sigma_{i, j}$ defines the constraint strength. The penalization of structures is clearly seen in Eq. (1), where $\left(m_{i}-m_{j}\right)_{k}^{2} / \sigma_{i, j}^{2}$ is proportional to the square of the value of the variation $\left(m_{i}-m_{j}\right)$. This implies that an increase in model parameter variation will always result in a penalization in the stabilizer. The smoothness regularization thus prevents reconstruction of sharp transitions.

The second regularization method is the minimum gradient support (Portniaguine and Zhdanov, 1999; Blaschek et al., 2008; Vignoli et al., 2015), which allows for large sharp vertical and horizontal model transitions. The minimum gradient support regularization seeks to minimize the spatial variations vertically and laterally by penalizing the vertical and horizontal model gradients through the stabilizer expressed as (Vignoli et al., 2015)

$$
\frac{\left(m_{i}-m_{j}\right)^{2} / \sigma_{i, j}^{2}}{\left(m_{i}-m_{j}\right)^{2} / \sigma_{i, j}^{2}+1} \text {. }
$$

In Eq. (2), $\sigma_{i, j}$ is a parameter used to control the sharpness of the regularization constraints. The stabilizer contribution to the objective function is thus one when $\left|m_{i}-m_{j}\right| \gg \sigma_{i, j}$ and zero when $\sigma_{i, j} \gg\left|m_{i}-m_{j}\right|$. The minimum gradient support functional thus counts the number of model variations larger than $\sigma_{i, j}$ for the stabilizer term of the objective function. This formalism allows sharp vertical and horizontal model transitions, which are penalized excessively by the smoothness-constrained inversion.

The geophysical voxel inversion is carried out on the logarithm of the resistivity values $(m=\log (\rho))$, and the constraint values are expressed in terms of constraint factors
CFs, representing the relative strength of the constraints (Auken et al., 2014). The actual values of the constraint standard deviations $\sigma_{i, j}$ of Eqs. (1) and (2) are then computed as $\sigma_{i, j}=\log \left(\mathrm{CF}_{i, j}\right)$. For instance, a constraint factor value of $\mathrm{CF}_{i, j}=1.9$ gives $\left(m_{i}-m_{j}\right)^{2} / \sigma_{i, j}^{2}=1$ in Eq. (1) when $\rho_{i} / \rho_{j}=1.9$, i.e., when the resistivity values are $90 \%$ different (Vignoli et al., 2015).

\subsection{Hydrological model parameterization}

In the second step (Fig. 1, box 2), the 3-D distribution of electrical resistivity values is linked to the hydrological parameters (i.e., hydraulic conductivity) through a spatially varying petrophysical relationship. Shape factors of this relationship are calibrated.

Linking hydraulic conductivity and electrical resistivity is not trivial because the parameter values and the form of the petrophysical relationship may vary dramatically between different types of environments. In addition, there can be fundamental questions about how the effective properties controlling electrical current flow are related to the effective properties controlling fluid flow (Slater, 2007). The primary factors controlling this relationship are porosity, pore water conductivity, tortuosity, grain size, degree of saturation, amount of clay minerals, etc. (McNeill, 1980). The simplest petrophysical relationship is the empirical relationship known as Archie's law (Archie, 1942), which relates porosity, pore water conductivity, and the degree of saturation to bulk electrical conductivity. However, this type of relationship does not take the electrical surface conductance of clay minerals into account. The Waxman and Smits model (Waxman and Smits, 1968) combined with the dual-water model by Clavier et al. (1984) provides a basis for establishing empirical relationships for shaly sand and sediments containing clays (Revil and Cathles, 1999; Revil et al., 2012). For glacial sedimentary environments, it is reported that clay has low electrical resistivity and also low hydraulic conductivity, and sand has high electrical resistivity and high hydraulic conductivity (Mazáč et al., 1985). For these environments, it is common to use a power law relationship, which is given some theoretical support by Purvance and Andricevic (2000). The relationship is expressed as

$K=\alpha \cdot \rho^{\beta}$,

where $K$ is the hydraulic conductivity $\left(\mathrm{m} \mathrm{s}^{-1}\right), \rho$ is the electrical resistivity (ohm m), and $\alpha$ and $\beta$ are two empirical shape factors. To compute $K$ for each element in the groundwater model grid, $\alpha$ and $\beta$ need to be parameterized and estimated. We suggest making the parameterization by pilot points placed in a regular grid in each layer of the groundwater model (Certes and De Marsily, 1991; Doherty, 2003). Each pilot point holds a set of $\alpha$ and $\beta$ parameters, and kriging is used for spatial interpolation of $\alpha$ and $\beta$ from the pilot points to the model grid. This kind of parameterization creates smooth transitions in the parameter fields and allows for 
variation in both the horizontal and vertical directions of the $\rho$ to $K$ translation. Hydraulic conductivity can thus be calculated by Eq. (3) for every element in the groundwater model grid.

\subsection{Hydrological inversion}

The model parameters, $\alpha$ and $\beta$ at the pilot points, are calibrated by fitting the groundwater model to hydrological data. When the number of model parameters is large compared to the number of observation data, the minimization must be stabilized by regularization. The total objective function to be minimized is therefore a balanced compromise between a measurement term $\left(\Phi_{m}\right)$ and a regularization term $\left(\Phi_{\mathrm{r}}\right)$. The combined objective function has the form

$$
\begin{aligned}
\Phi_{\text {total }} & =\Phi_{m}+\mu \cdot \Phi_{\mathrm{r}} \\
& =\sum_{i=1}^{n} \omega_{d, i}\left(d_{\mathrm{obs}, i}-d_{\mathrm{sim}, i}\right)^{2}+\mu \cdot \Phi_{\mathrm{r}}
\end{aligned}
$$

where $\Phi_{\text {total }}$ is the total objective function, $d_{\mathrm{obs}, i}$ and $d_{\mathrm{sim}, i}$ are measured and equivalent simulated data values, $\omega_{\mathrm{di}}$ is a data-dependent weight, $\mu$ is a weight factor, and $\phi_{\mathrm{r}}$ is a Tikhonov regularization term. Here, $\phi_{\mathrm{r}}$ is defined as preferred difference regularization, where the preferred difference between neighboring parameter values is set to zero. $\Phi_{\text {total }}$ is minimized iteratively, and the regularization weight factor, $\mu$, is calculated during the iteration to ensure that $\Phi_{m}$, the measurement part of the objective function, becomes approximately equal to a user-specified target value (Doherty, 2010).

\section{Synthetic example}

For illustrative purposes, we use a 3-D synthetic system very similar to that presented by Christensen et al. (2016). The only difference is that the active part of the groundwater system only consists of 5 layers, whereas Christensen et al. (2016) used a 20-layer model.

\subsection{Groundwater reference system and hydrological data}

The groundwater system is intended to mimic a glacial landscape and covers an area that is $7000 \mathrm{~m}(\mathrm{~N}-\mathrm{S})$ by $5000 \mathrm{~m}$ $(\mathrm{E}-\mathrm{W})$. The geology of the system was generated using $\mathrm{T}$ PROGS (Carle, 1999) as having a horizontal discretization of $25 \mathrm{~m} \times 25 \mathrm{~m}$ and a vertical discretization of $10 \mathrm{~m}$. The system extends $50 \mathrm{~m}$ in the vertical direction, where it reaches impermeable clay with a horizontal surface. The T-PROGS generated geology above the impermeable clay consists of categorical deposits of sand, silt, and clay. Within each of the three types of deposits, hydraulic conductivity, recharge, and porosity were generated as horizontally correlated random fields using FIELDGEN (Doherty, 2010). All bound-

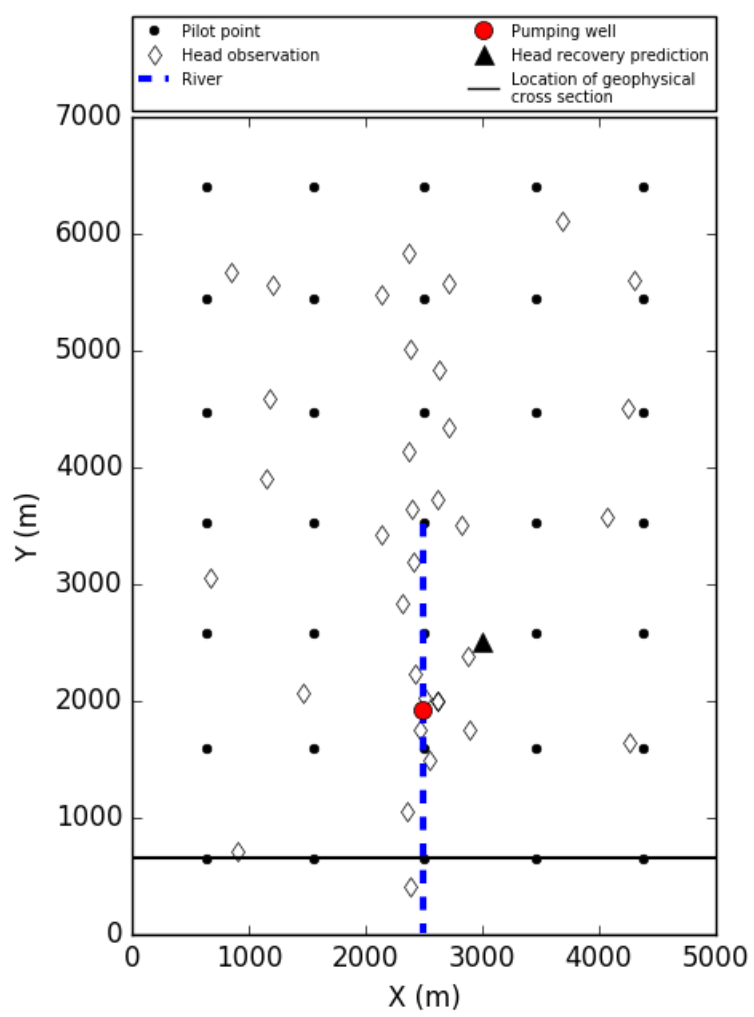

Figure 2. A map of locations of boreholes, a pumping well, pilot points, head recovery prediction, and location of a geophysical cross section.

aries of the domain were defined as having no-flow conditions, except the southern boundary where hydraulic head was defined as constant, $h=0 \mathrm{~m}$. The local recharge depends on the type of sediment at the uppermost layer. Most groundwater discharges through the southern boundary, but approximately $35 \%$ discharges into a river running north to south in the middle of the domain (Fig. 2). Groundwater flow was simulated as confined steady-state flow employing MODFLOW-2000 (Harbaugh et al., 2000) with the spatial discretization equal to the geological discretization. Groundwater is pumped at a rate of $0.015 \mathrm{~m}^{3} \mathrm{~s}^{-1}$ from a well located at $x=2487.5 \mathrm{~m}$ and $y=1912.5 \mathrm{~m}$ and the well screens the deepest $10 \mathrm{~m}$ of the groundwater system. In the following, this system is called the reference system.

Thirty-five boreholes are found within the domain (Fig. 2). Each borehole contains a monitoring well that screens the deepest $10 \mathrm{~m}$ of sand registered in the borehole. For each system realization, the hydraulic head in the 35 wells and the river discharge at the southern boundary were extracted from a forward simulation made by MODFLOW-2000. The 35 simulated hydraulic head values were contaminated by independent Gaussian error with zero mean and $0.1 \mathrm{~m}$ standard deviation. The river discharge was corrupted with independent Gaussian error with zero mean and a standard deviation corresponding to $10 \%$ of the true river discharge. The 
36 contaminated values constitute the hydrological data used for groundwater model calibration.

\subsection{Geophysical reference system and data}

The geophysical reference system was designed so that there is perfect correlation between hydraulic conductivity and electrical resistivity. This implies that a relationship between hydraulic conductivity and measured electrical resistivity is likely to exist. The true relationship is of the same form as Eq. (3), and it uses constant shape factor values $\alpha=1 e^{-12}$ and $\beta=4$. This corresponds to conditions where clay has low electrical resistivity and also low hydraulic conductivity, and sand has high electrical resistivity and high hydraulic conductivity. The impermeable clay at the base of the reference system was assigned a constant value of $5 \mathrm{ohm} \mathrm{m}$.

The AEM data were simulated using AarhusInv (Auken et al., 2014) for a system setup similar to a typical dualmoment SkyTEM-304 system (Sørensen and Auken, 2004). The simulated survey consists of $35 \mathrm{E}-\mathrm{W}$ flight lines with $200 \mathrm{~m}$ spacing between the flight lines. AEM system responses were simulated for every $25 \mathrm{~m}$ along the flight lines, giving a total of 6300 sounding locations for both the transmitted high and low moments. AarhusInv is a 1-D modeling code. To mimic the loss of resolution with layer depth we simulated the responses using the 2-D logarithmic average resistivity of all model cells inside the radius of the footprint at a given depth. To obtain the geophysical data set, the simulated data were contaminated with noise according to the noise model suggested by Auken et al. (2008):

$V_{\text {resp }}=V \cdot\left(1+G(0,1) \cdot\left[\operatorname{SD}_{\text {uni }}^{2}+\left(\frac{V_{\text {noise }}}{V}\right)^{2}\right]^{1 / 2}\right)$,

where $V_{\text {resp }}$ is the perturbed synthetic data, $V$ is the synthetic noiseless data, $G(0,1)$ is standard Gaussian noise (with zero mean and unit standard deviation), and $\mathrm{SD}_{\text {uni }}^{2}$ is uniform noise variance. $V_{\text {noise }}$ is the background noise contribution given by

$V_{\text {noise }}=b \cdot\left(\frac{t}{10^{-3}}\right)^{-1 / 2}$,

where $t$ is the gate center time in seconds, and $b$ is the background noise level at $1 \mathrm{~ms}$. For the following analysis we generated geophysical data sets with four levels of background noise, i.e., $b$ equal to $1,3,5$, and $10 \mathrm{nV} \mathrm{m}^{-2}$, respectively. The uniform standard deviation, which accounts for instrument and other non-specified noise contributions, was set to $3 \%$ for $\mathrm{d} B / \mathrm{d} t$ responses. After the data were perturbed with noise, they were processed as a field data set (Auken et al., 2009), resulting in an uneven number of gates per sounding. Figure 3 illustrates the resulting low and highmoment AEM sounding data, respectively, for the different background noise levels.
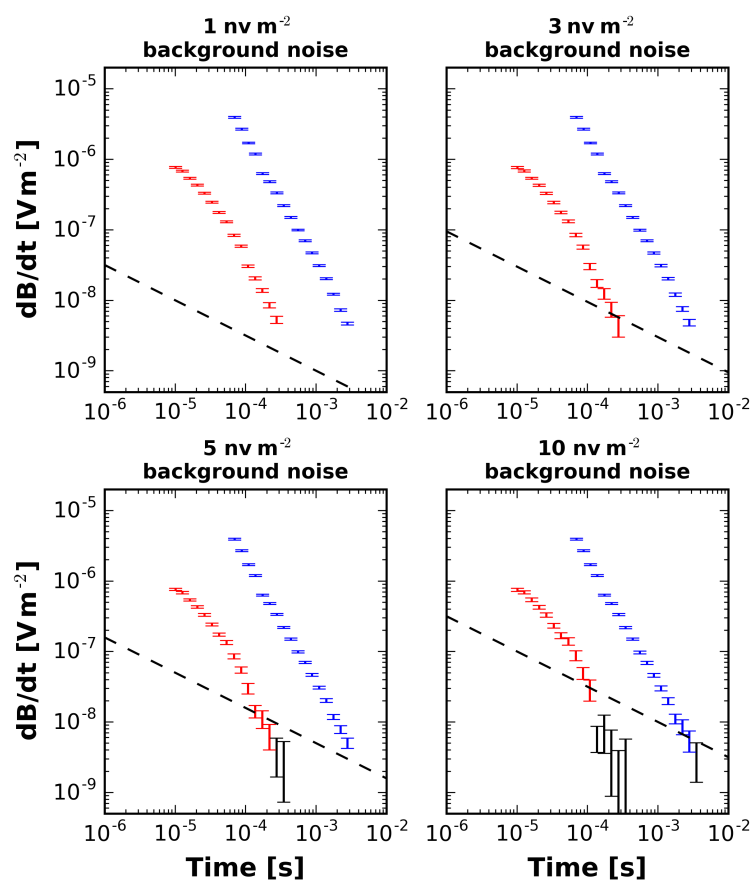

Figure 3. AEM sounding data corrupted by four levels of background noise. The value on top of each subplot corresponds to the noise level at $1 \mathrm{~ms}$ and to the $b$ value in Eq. 6 . The black dashed curves indicate the background noise levels, low and high-moment earth responses are illustrated as red and blue error bars, respectively, and the black error bars illustrate data which are removed by the data processing.

\subsection{Geophysical voxel inversion}

The geophysical data were inverted by voxel inversion (Fiandaca et al., 2015) using AarhusInv (Auken et al., 2014). The voxel inversion was conducted in two different ways: by using L2-norm "smooth" constraints, or by using minimum gradient support "sharp" constraints (both implemented in AarhusInv; Auken et al., 2014).

To avoid the influence of numerical discretization errors, the geophysical voxel inversion uses the same spatial discretization as the reference system and the groundwater model. For both smooth and sharp inversions, a $40 \mathrm{ohm} \mathrm{m}$ uniform half-space was used as the starting model and spatial regularization was applied using the same settings throughout all inversions. Considering the small number of layers and the shallow discretization, it was unnecessary to apply vertical constraints for any of the inversions. By contrast, depth- and direction-dependent horizontal constraint factors were used for both smooth and sharp inversions. The strength given to the horizontal constraints is based on experience, keeping in mind that the constraint factors should not prevent data fitting, but promote model consistency. Therefore, a few experiments were made to "manually" tune the magnitude of the constraint factors. Different values along the flight lines and perpendicular to them, respectively, were found to give 
better results. This is a result of having higher data density along the flight lines compared to the perpendicular direction. In these synthetic tests (similar to what is done with field data with analogous data density) the smooth regularization constraint factors of $\mathrm{CF}=1.9$ along the flight lines and $\mathrm{CF}=1.05$ perpendicular to the flight lines were used for the first layer.

In contrast to the conventional inversion of geophysical data, where the vertical discretization of the geophysical model is normally characterized by logarithmically increasing layer thicknesses, in this study fixed layer thicknesses were used in the geophysical models. To account for the loss of resolution with depth without increasing the layer thicknesses, the horizontal constraint factors were set to decrease linearly with depth (tighter bands for the deeper layers), resulting in constraint factors of 1.4 along the flight lines and 1.02 perpendicular to the flight lines for the sixth layer.

The same directional and depth-dependent tuning used for smooth regularization was also applied to the sharp inversion. In this case constraint factors of $\mathrm{CF}=1.0625$ along the flight lines and 1.01 perpendicular to the flight lines were used for the first layer, while factors of $\mathrm{CF}=1.025$ along the flight lines and $\mathrm{CF}=1.01$ perpendicular to the flight lines were used for the sixth layer. The smaller values of the constraint factors in the sharp inversion are due to the different role that the factors play in the regularization definition, as is evident when comparing Eqs. (1) and (2). The difference in constraint values between smooth and sharp inversion is analogous to what has been used in other studies (e.g., Vignoli et al., 2015). All the constraint values used in this study represent typical values working also in other applications, both for synthetic and filed data.

\subsection{Groundwater model parameterization and calibration}

In the following, the groundwater model will be parameterized in two different ways. Both approaches treat the shape factors between hydraulic conductivity and resistivity, $\alpha$ and $\beta$, in a relationship (Eq. 3), as spatially dependent parameters to be estimated. The two parameterizations differ by the resistivity model that is used to calculate the hydraulic conductivity field of the groundwater model.

- The first type of parameterization uses a resistivity model estimated by smooth voxel inversion of AEM data collected with a background noise level of $3 \mathrm{nV} \mathrm{m}^{-2}$. These models will be referred to as SHIsmooth-3.

- The second type of parameterization uses a resistivity model estimated by sharp voxel inversion of AEM data collected with a background noise level of either 1, 3, 5, or $10 \mathrm{nV} \mathrm{m}^{-2}$. These models will be referred to as SHIsharp-1, SHI-sharp-3, SHI-sharp-5, and SHI-sharp-10, respectively.
The shape factors, $\alpha$ and $\beta$, of the petrophysical relationship are parameterized by placing pilot points in a uniform grid, with five nodes in the $x$ direction and seven in the $y$ direction. Hence, in total the groundwater model is parameterized by $5 \times 7 \times 5=175$ petrophysical relationships, each having two parameters (the shape factors).

The parameter values are estimated by fitting the available hydrological data consisting of the 35 observations of the hydraulic head and one river discharge observation. Calibration is done by minimization of the total objective function given by Eq. (4), where the measurement objective function is computed as

$$
\begin{gathered}
\Phi_{m}=n_{\mathrm{h}}^{-1} \sum_{i=1_{\mathrm{h}}}^{n} \omega_{\mathrm{h}}\left(h_{\mathrm{obs}, i}-h_{\mathrm{sim}, i}\right)^{2} \\
+n_{\mathrm{r}}^{-1} \sum_{i=1}^{n_{\mathrm{r}}} \omega_{\mathrm{r}}\left(r_{\mathrm{obs}, i}-r_{\mathrm{sim}, i}\right)^{2},
\end{gathered}
$$

where $n_{\mathrm{h}}$ and $n_{\mathrm{r}}$ are the number of head and river measurements, respectively; $h_{\text {obs }}$ and $h_{\text {sim }}$ are observed and corresponding simulated hydraulic heads; $r_{\mathrm{obs}}$ and $r_{\mathrm{sim}}$ are observed and corresponding simulated river discharge; and $\omega_{\mathrm{h}}$ and $\omega_{\mathrm{r}}$ are subjectively chosen weights for head and discharge data, respectively. If a model is expected not to have structural defects, then it would be ideal to choose the weights $\omega_{\mathrm{h}}=\sigma_{\mathrm{h}}^{-1}$ and $\omega_{\mathrm{r}}=\sigma_{\mathrm{r}}^{-1}$, where $\sigma_{\mathrm{h}}$ and $\sigma_{\mathrm{r}}$ are the standard deviations of measurement error for head and river measurements, respectively. However, in this case (as in all real cases) the model has structural errors that make the misfit between hydraulic head data and equivalent simulated values much larger than what can be explained by measurement error. In accordance with common groundwater modeling practice (e.g., Christensen et al., 1998), we therefore conducted residual analysis and a few experiments to estimate the magnitude of the total head error (which is the sum of observation error and structural error). This indicated that the standard deviation for the total error on the hydraulic head is approximately $10 \cdot \sigma_{\mathrm{h}}$, while the total error for the river discharge is totally dominated by measurement error. As weights we therefore used $\omega_{\mathrm{h}}=\left(10 \cdot \sigma_{\mathrm{h}}\right)^{-2}=1.0$ and $\omega_{\mathrm{r}}=\left(\sigma_{\mathrm{r}}\right)^{-2}=1.38 \cdot 10^{5}$, respectively. Using these weights, and averaging over the 20 system realizations, gave a minimized objective function value of $\bar{\phi}_{m}=2.5$. This is close to the value of 2.0, which would be expected from (Eq. 7) if the weighting used reflects the error magnitudes.

Calibration was performed using BeoPEST, a version of PEST (Doherty, 2010) that allows the inversion to run in parallel using multiple cores and computers.

It should be noted that for calibration and model prediction we applied the recharge field and boundary conditions of the reference system. 


\subsection{Model predictions}

In step 3 (Fig. 1, box), the calibrated groundwater model is used to make predictions.

In the following synthetic demonstration study, the calibrated SHI-smooth and SHI-sharp groundwater models are evaluated by comparing their simulated model predictions with corresponding predictions simulated for the (synthetic and, therefore, known) reference system. The former are called "model predictions"; the latter are called "reference predictions".

Prediction types 1 and 2 relate to steady-state flow when groundwater is pumped from the well. This is also the condition for which the hydrologic data used for calibration were sampled. Type 1 is the average age of the groundwater pumped from the well. Type 2 is the size of the recharge area of the pumping well. Both of these predictions differ in type from the calibration data. For these model predictions, we used a homogeneous porosity of 0.2 (the average value of the reference system porosity fields is 0.184 ).

Prediction types 3 and 4 relate to a new stress situation long after pumping from the well has ceased: type 3 is groundwater discharge into the stream, and type 4 is head recovery for a well screening a layer northeast of the pumping well (the location is shown in Fig. 2).

Reference and model prediction types 3 and 4 were simulated by MODFLOW-2000 (Harbaugh et al., 2000), while types 1 and 2 were simulated by forward particle tracking using MODPATH version 5 (Pollock, 1994) and MODFLOW2000 results.

The first two types of prediction are interesting from the perspectives of protection and resource management of a well field, while the latter two are relevant in the case of possible change in management practice resulting in a new stress.

\subsection{Evaluation of prediction performance}

As said at the beginning of Sect. 2, steps 1-3 of the framework can be repeated for a number of system realizations to provide consistent statistical interference regarding the model prediction results. Here, 20 different reference system realizations were used. For each prediction, we therefore have 20 corresponding sets of reference predictions and model predictions that can be used to evaluate the performance of a calibrated model with respect to that prediction. The performance is evaluated for the SHI-smooth and SHIsharp models, respectively, and it is done in the following ways.

Prediction error characteristics are quantified by the mean absolute error (MAE), the mean error (ME) following

$\operatorname{MAE}=\frac{1}{N} \sum_{i=1}^{N}\left|x_{i}-t_{i}\right|$,

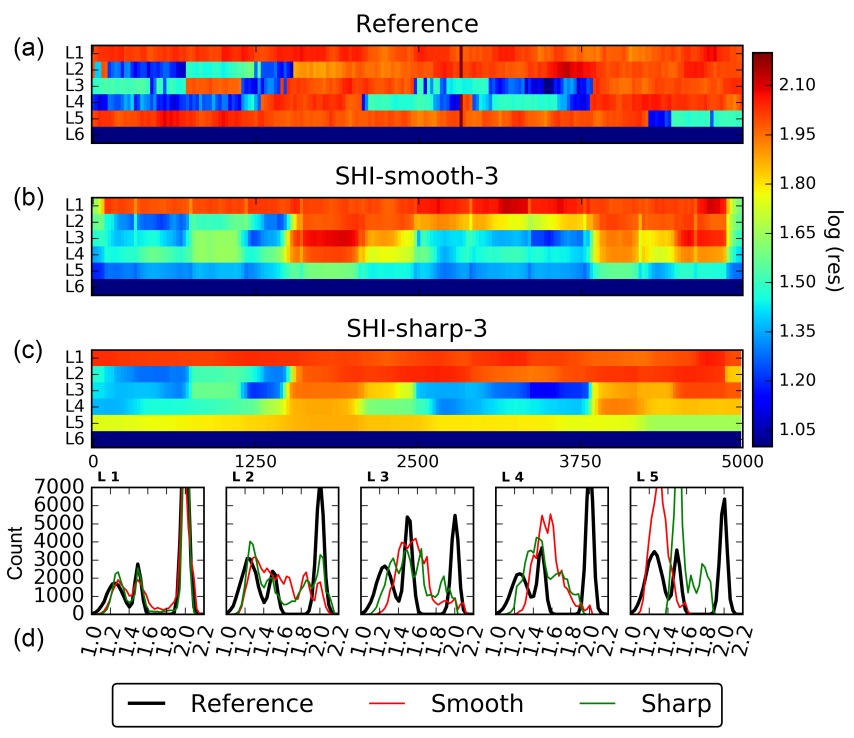

Figure 4. The figure shows an east-west cross section of resistivity for the reference system (realization number 20), and inversion results for smooth and sharp inversion, respectively. The last row shows a histogram of resistivity for each layer. The black curve is the resistivity distribution for the reference system, the red curve shows the resistivity distribution for the smooth inversion, and finally the green curve shows the resistivity distribution for the sharp inversion.

$\mathrm{ME}=\frac{1}{N} \sum_{i=1}^{N} x_{i}-t_{i}$

where $x_{i}$ is the model prediction of realization $i, t_{i}$ is the reference prediction of realization $i$, and $N=20$ is the number of system realizations. MAE measures how close the model prediction tends to be to the reference prediction; ME measures the tendency of positive or negative bias in the model prediction.

\section{Results}

\subsection{Geophysical results}

Figure 4 shows a representative cross section for 1 of the 20 system realizations. Both geophysical models in Fig. 4 were inverted using data perturbed with a background noise level of $3 \mathrm{nV} \mathrm{m}^{-2}$. Comparing the geophysical model results with the reference model, we find that SHI-smooth- 3 resolves the main features reasonably well for the upper layers. The main discrepancy is found in the fifth layer, where the sand bodies are not resolved. In general, the resistivity of the sand bodies (dark orange in the reference system) is underestimated, and the transitions between the categorical deposits are artificially smooth. 


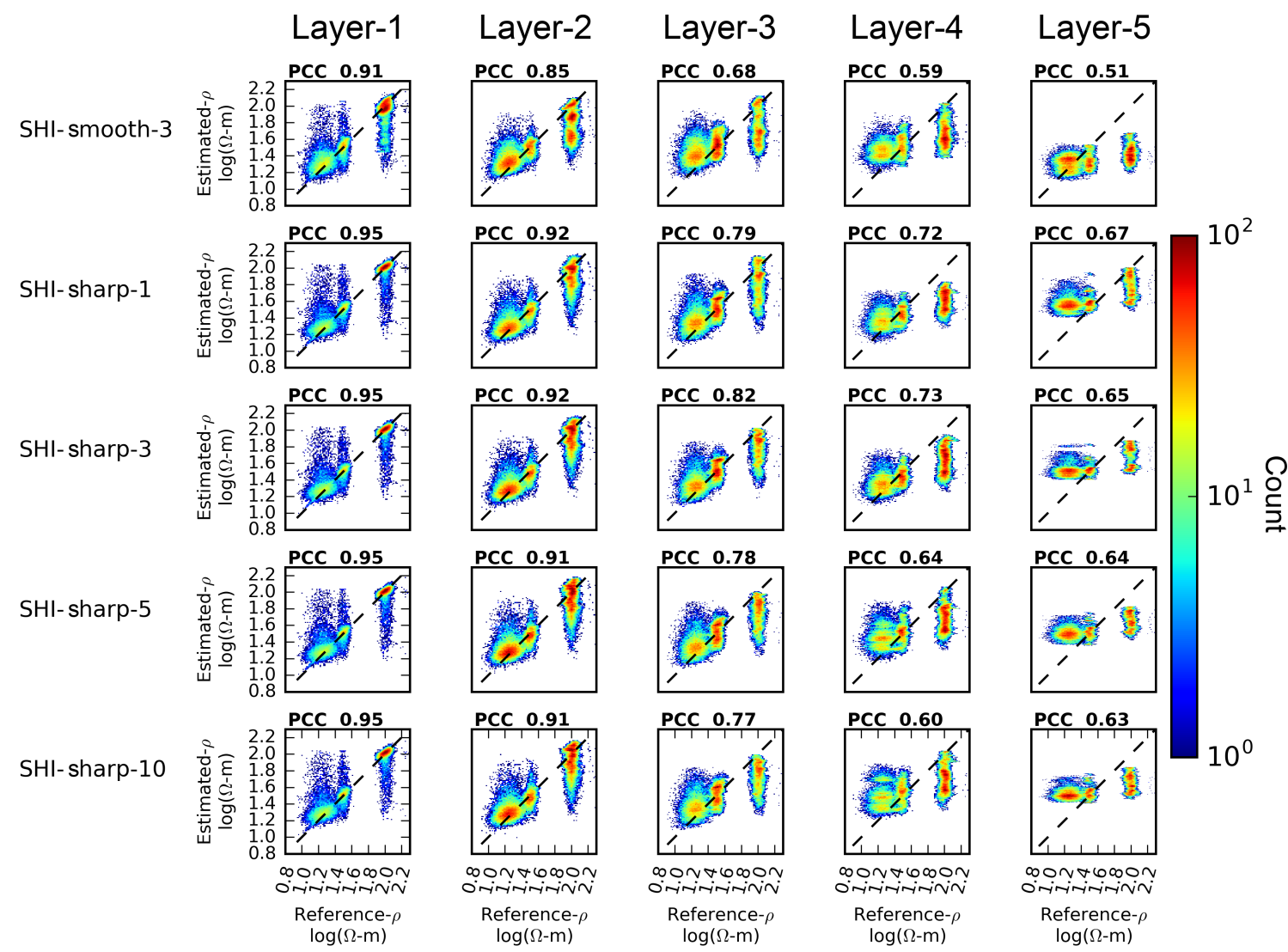

Figure 5. Scatter plot of true and estimated electrical resistivity fields for smooth geophysical inversion and sharp geophysical inversion for different data qualities of the AEM data for model realization number 20. On top of each window a Pearson correlation coefficient (PCC) is calculated.

Figure 4 shows that SHI-sharp-3 resolves the sand body in layer 5 much better than SHI-smooth-3. Moreover, the locations and boundaries of the geological deposits tend to be less smeared out when using the sharp constraints. Inspection of the histograms at the bottom of Fig. 4 shows that the SHI-sharp-3 model tends to produce resistivity distributions that are more similar to the reference distributions than the SHI-smooth-3 model. This improvement could allow for easier translation from electrical resistivity into hydraulic conductivity and correspondingly more faithful representation of hydrogeologic structure and connectivity.

Figure 5 shows voxel-by-voxel density plots of reference versus estimated electrical resistivity for a SHI-smooth model and corresponding SHI-sharp models. Pearson's correlation coefficient (PCC; Cooley and Naff, 1990) is shown on top of the density plot for each layer. A comparison of the density plots and the PCC values of the SHI-smooth-3 and SHI-sharp-3 models shows that using sharp instead of smooth constraints improves the inverted geophysical model. The improvement is seen most clearly for the sand deposits.

For both the SHI-smooth and SHI-sharp models there is a strong correlation between the electrical resistivity estimates and the true electrical resistivities of the first layer, but the SHI-smooth model has weaker correlation than the SHI-sharp models. For both types of models, the correlation weakens with depth and background noise. The former is caused by the resolution limitations of AEM data. However, the depth and resistivity of the low-resistivity clay at the base of the model are well resolved by both the SHI-smooth and SHI-sharp model inversions (results not shown).

\subsection{Hydrological calibration results}

The calibration results for the 20 different system realizations are shown in Fig. 6. The figure shows that the measurement objective function value, $\Phi_{m}$, for most system realizations is close to 2.0. This is the case for almost all of the SHI-sharp model realizations, even for large background noise levels. For many of the realizations, the SHI-smooth model also fits the data well; but, several realizations lead to higher misfit than desired. This makes $E\left[\Phi_{m}\right]$ equal to 5.8 for the SHIsmooth-3 models, while it is 2.5 for the SHI-sharp-3 models. That is, the estimated hydraulic conductivity field tends to be better for sharp models than for smooth models. 

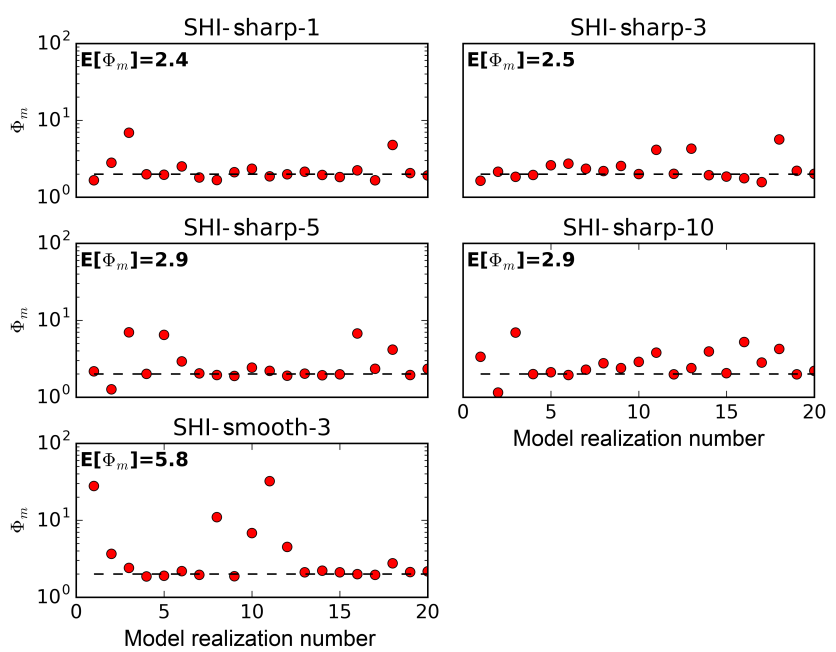

Figure 6. Measurement objective function value obtained for the various groundwater model calibration cases, while $E\left[\Phi_{m}\right]$ is the mean value across all 20 different system realizations. The dashed line indicates the expected target value for the model calibrations.

\subsection{Parameter estimation}

Figure 7 shows a cross section of the estimated $K$-, $\alpha$ - and $\beta$-fields for one of the system realizations. The two columns show estimates for the SHI-smooth-3 and SHI-sharp-3 models. Figure 8 shows a density plot of the reference hydraulic conductivity distribution and the estimated hydraulic conductivity distributions. The results in Figs. 7 and 8 are typical for all 20 system realizations.

From Fig. 7a and $\mathrm{b}$ it is seen that the estimated $\alpha$ and $\beta$ parameter values change smoothly in the horizontal direction but have sharp transitions in the vertical direction. The second row of Fig. 7 shows the corresponding estimated $K$ fields whose main features are determined by the underlying resistivity models (Fig. 4), but they are "corrected" during model calibration to make the groundwater model fit the hydrological data.

For the SHI-smooth-3 model, $\alpha$ and $\beta$ take compensatory roles, particularly in the first layer. Here, the estimated $\alpha$ and $\beta$ values are higher than the shape factors of the true relationship that was used to construct the geophysical reference system. This increases the hydraulic conductivity in layer 1 to compensate for the too low hydraulic conductivity (and resistivity, Fig. 4) in layer 2 and deeper layers. The estimated $\alpha$ and $\beta$ values are not sufficient to compensate for the missing deep high-resistivity body in layer 5 of the SHI-smooth-3 model (Fig. 4).

For the SHI-sharp-3 model, the estimated $\alpha$ and $\beta$ parameter values only vary slightly from the shape factor values of the true relationship, except for layer 5 (Fig. 7b). This indicates that for the shallower layers the sharp inversion of AEM data sufficiently resolves the resistivity of features that are important for groundwater model calibration. In layer 5

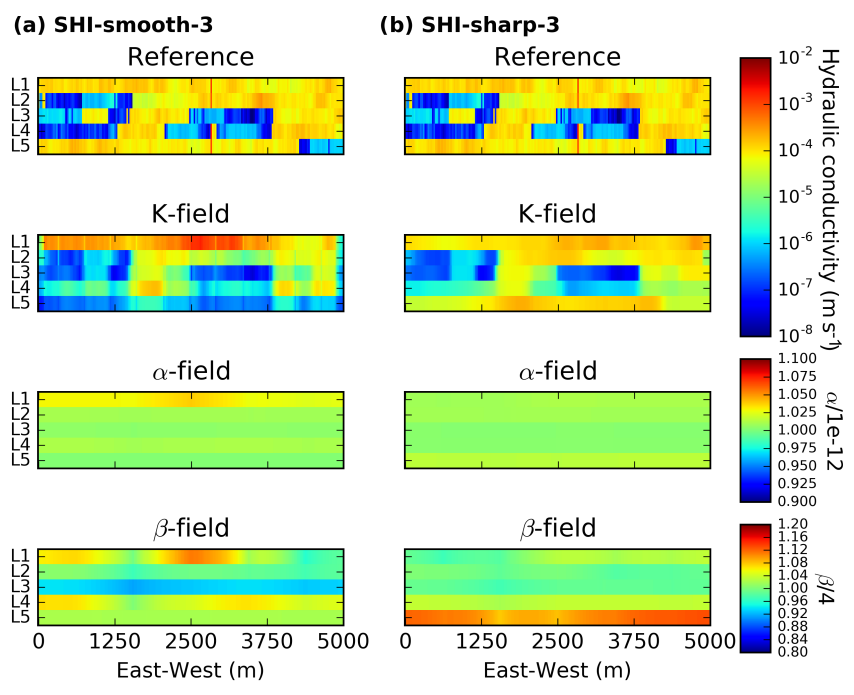

Figure 7. East-west cross section for model realization number 20. (a) shows the parameter fields for the SHI-smooth-3 calibrated model. (b) shows the parameter fields for the SHI-sharp-3 calibrated model. The first row shows the reference $K$-field, the second row shows the estimated $K$-field, and the third and fourth rows show shape factors of the petrophysical relationship for $\alpha$ and $\beta$, respectively.

the estimate of shape factor $\beta$ turns out to be fairly high to compensate for the too low resistivity estimates in this layer (Fig. 4).

Figure 8 shows voxel-by-voxel density plots of reference versus estimated hydraulic conductivity for the SHI-smooth and SHI-sharp models. The results confirm that the $K$ field tends to be overestimated for the first layer, in particular for the SHI-smooth-3 model. From the second layer and deeper, the hydraulic conductivity values tend to be underestimated for sand but overestimated for silt and clay. Moreover, the distributions of estimated $K$ smear out with depth. Judged by PCC values and visual inspection of Fig. 8 (highlighting the connectivity of the $K$ field), the hydraulic conductivity field estimated for any SHI-sharp model is in better agreement with the reference field than the field estimated by the SHI-smooth-3 model.

Model structural accuracy is quantified in Table 1 for both the SHI-smooth and SHI-sharp models. Structural accuracy is calculated here as the fraction of the total number of voxels for which the estimated $\log _{10}$-hydraulic conductivity plus/minus $20 \%$ contains the true $\log _{10}$-hydraulic conductivity value of the reference model. The results are averaged over the 20 system realizations. From Table 1 it is seen that all SHI-sharp models outperform the accuracy of the SHIsmooth models, except for layer 5. The exception occurs because the SHI-smooth models are fairly good at estimating the $K$ distributions for silt and clays, but underestimate $K$ for sand (Fig. 8). In contrast, SHI-sharp models overestimate the $K$ distributions for silt and clays, but only slightly underes- 


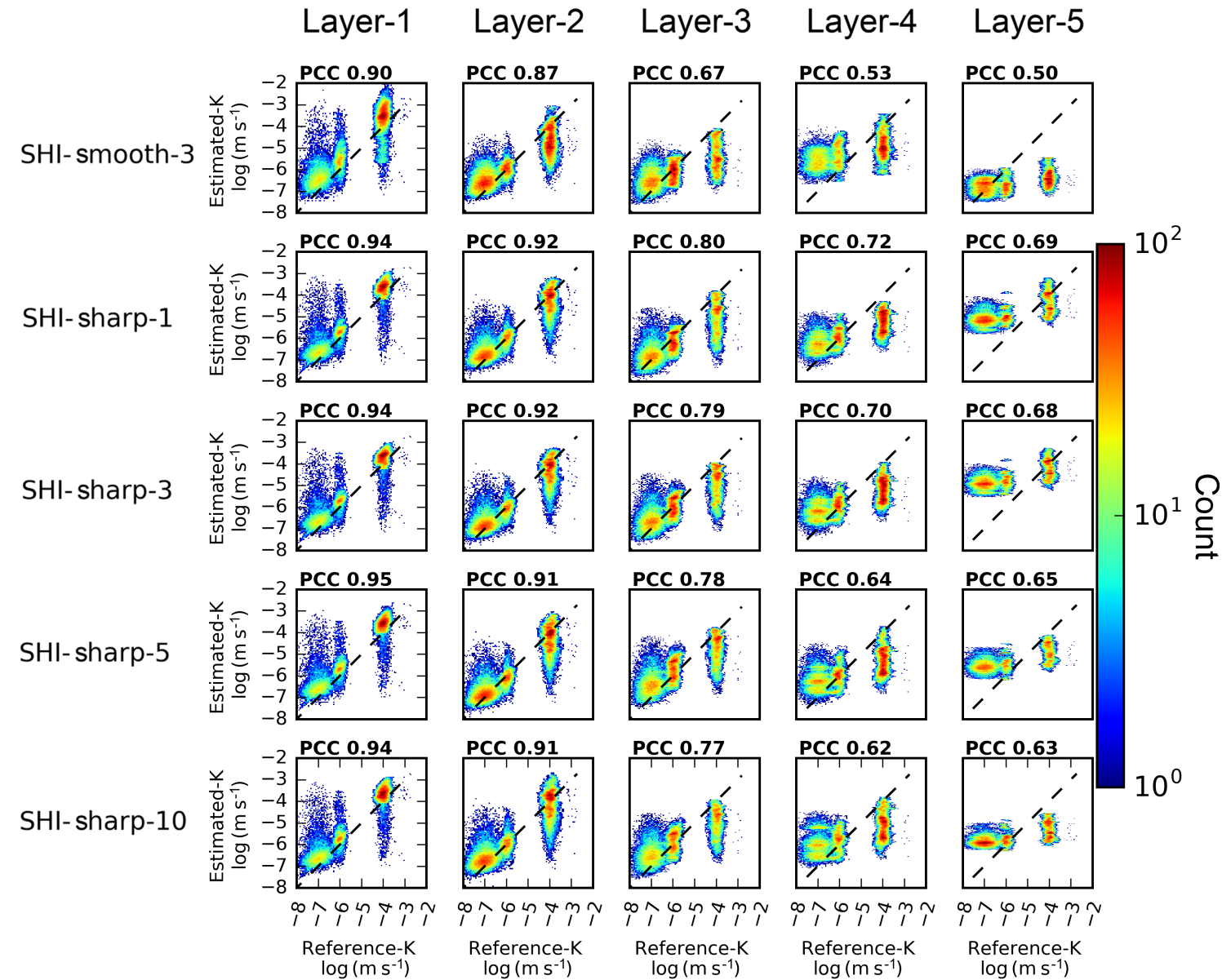

Figure 8. Scatter plot of true and estimated hydraulic conductivity fields for smooth geophysical inversion and sharp geophysical inversion for different data qualities of the AEM data for model realization number 20. On top of each window the Pearson correlation coefficient (PCC) is calculated.

Table 1. Model structural accuracy comparison for the groundwater model using both smooth or sharp geophysical models and different background noise levels. The results are averaged over the 20 system realizations. A value of 1.0 means that the model's hydraulic conductivity field is in good agreement with the reference field; a value of 0.0 means no agreement (see the body text for an exact definition of "structural accuracy").

\begin{tabular}{lrrrrr}
\hline & Layer 1 & Layer 2 & Layer 3 & Layer 4 & Layer 5 \\
\hline SHI-3 smooth & 0.89 & 0.79 & 0.56 & 0.54 & 0.64 \\
SHI-1 sharp & 0.96 & 0.91 & 0.81 & 0.61 & 0.48 \\
SHI-3 sharp & 0.96 & 0.92 & 0.82 & 0.64 & 0.5 \\
SHI-5 sharp & 0.96 & 0.91 & 0.78 & 0.64 & 0.49 \\
SHI-10 sharp & 0.96 & 0.90 & 0.78 & 0.6 & 0.46 \\
\hline
\end{tabular}

timate $K$ for sand (Fig. 8). Therefore, for layer 5, the model structural accuracy appears to be better for SHI-smooth than for SHI-sharp models.

\subsection{Prediction results}

For each of the 20 system realizations, the calibrated groundwater models were used to make the model predictions described in Sect. 3.5. Figure 9 shows scatter plots of the reference prediction versus the calibrated model prediction; each plotted point corresponds to a particular system realization and the corresponding SHI-smooth-3 or SHI-sharp-3 model. The mean error (ME) and mean absolute error (MAE) of the prediction are also given in Fig. 9. Figure 10 shows a MAE contour map for head recovery predictions.

\subsubsection{Particle tracking predictions}

The first column of Fig. 9 shows results for prediction of the average age of the groundwater pumped from the pumping well. The scatter plot illustrates that SHI-sharp models tend to overpredict average age. This is seen by the majority of points plotting above the identity line as well as by the value of $\mathrm{ME}=32$ (Fig. 9). The age prediction results are similar for the SHI-smooth models, although the spread 

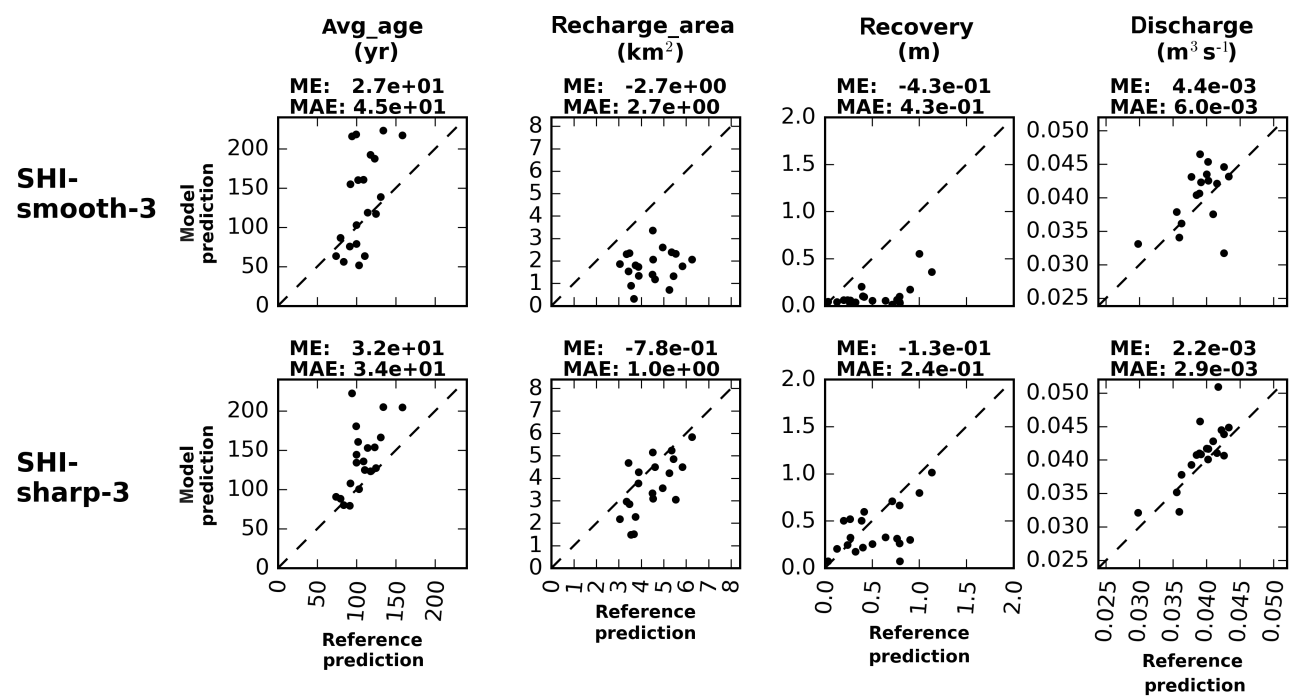

Figure 9. Scatter plots of calibrated model prediction versus the reference model prediction using results from the 20 system realizations. The plots in the first and second columns are the average groundwater age and recharge area, respectively, of the pumping well. Column three is for head recovery when pumping has stopped in the observation well shown in Fig. 10, and column four is for groundwater discharge to the river after pumping has ceased; ME and MAE are used to quantify the prediction error on the basis of the 20 realizations.

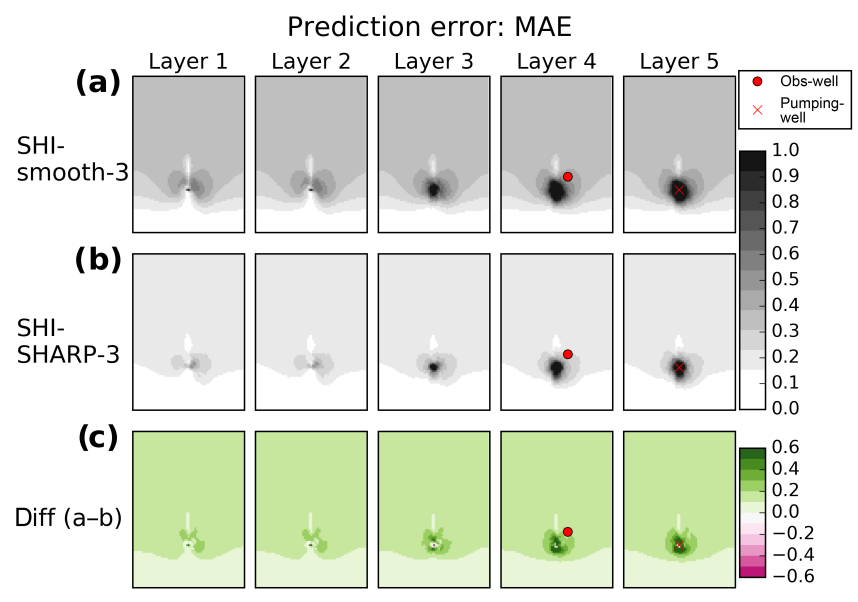

Figure 10. MAE contour map for head recovery prediction. (a) For predictions using the SHI-smooth models. (b) For predictions using the SHI-smooth models. (c) Difference between the maps shown in (a) and (b). Red dots mark the location of the observation well for the head recovery prediction shown in Fig. 9. The red cross marks the location of the pumping well.

of points is larger than for SHI-sharp-3 (e.g., quantified by the larger value of MAE). There are two major explanations for these relatively "poor" predictive performances. First, the calibrated $K$-fields underestimate the hydraulic conductivity of sand deposits in the deeper layers (Fig. 8), which results in too slow particle travel times at depth. Secondly, the reconstruction of the deepest layers is too smooth for both the SHI-smooth and SHI-sharp models (Fig. 7) and does not re- solve the small-scale variability that controls the transport of particles.

The second column of Fig. 9 reports results related to prediction of the recharge area of the pumping well. The scatter plot shows that the SHI-smooth models underpredict the recharge area. This happens because the smooth models lead to estimation of hydraulic conductivities in the deepest layers that are too low. This creates a deep cone of depression around the pumping well that extends upward locally to reach the river bed. This induces a local discharge of water from the stream through the groundwater system to the pumping well. These models thus predict that a significant proportion of the pumping will come from local discharge from the river. (This is compensated for by increased model predicted groundwater discharge to other parts of the river.) For the true, reference system used to generate the data, the river does not lose water, and all water pumped from the well originates from groundwater recharge.

The SHI-sharp models are better predictors of the recharge area, but these models also tend to predict an area that is too small. These models also predict local discharge from the river to the groundwater system, but to a lesser degree than the SHI-smooth models. This is likely because the main features of the reference system are better reconstructed by the SHI-sharp-3 models.

\subsubsection{Head recovery and discharge predictions}

The prediction of head recovery at an observation well (location shown in Fig. 10) is done poorly by SHI-smooth-3 (Fig. 9). The predicted head recovery is very small for most of these models because they tend to have too little hydraulic 


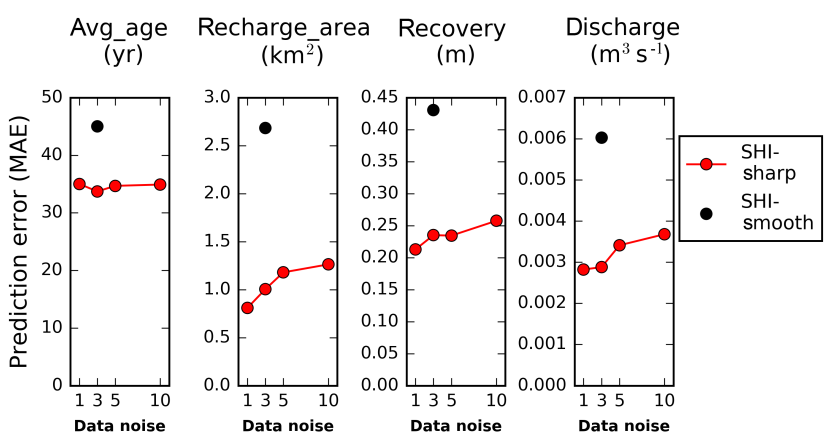

Figure 11. Prediction error as a function of the background noise on the geophysical data. The black dots are the SHI-smooth models using a background noise level of $3 \mathrm{nV} \mathrm{m}^{-2}$. The red dots are the SHI-sharp models as a function of background noise level.

connectivity between the deepest layers, the estimated hydraulic conductivities are too low in the deep sand layers, and the simulated cone of depression is therefore too deep and too local.

The SHI-sharp-3 models make less biased, fairly reasonable predictions of the head recovery (Fig. 9) because they resolve the variations of hydraulic conductivity at depth better than the SHI-smooth-3 models. The superiority of SHIsharp-3 models for recovery prediction is also seen from the MAE contour maps in Fig. 10. The MAE is seen to be spatially dependent: it is largest at the pumping well, and smallest at the constant head boundary to the south

The fourth column of Fig. 9 shows that both types of models are good predictors of discharge to the river after cessation of pumping. However, the SHI-sharp-3 model prediction is superior (its points plot closer to the identity line). For SHI-smooth-3, the prediction tends to be positively biased and more spread than for SHI-sharp-3.

\subsubsection{Prediction error as function of data quality}

In Fig. 11 MAE is used as a metric to evaluate how the prediction performance of SHI-sharp models depends on the level of background noise for the geophysical data. The noise levels were kept unchanged for the hydrological data.

Figure 11 shows that the average age prediction made by SHI-sharp models is nearly unaffected by the quality of the geophysical data. It is speculative, but this result may be because this prediction is highly dependent on small-scale variability in hydraulic conductivity and porosity that cannot be resolved from any of the geophysical data sets. That is, even the highest quality geophysical data are not highly informative, so reducing the data quality further has little effect.

It is different for the recharge area prediction (Fig. 11): MAE increases for this by approximately $25 \%$ when the level of background noise is increased from 1 to $10 \mathrm{nV} \mathrm{m}^{-2}$. This happens because the variations of resistivity (and thus hydraulic conductivity) are less well resolved when using the poor-quality geophysical data.

The third and fourth rows of Fig. 11 show the head recovery and river discharge prediction after cessation of the pumping well. Head recovery and discharge predictions also tend to depend on the quality of the geophysical data. The MAE increases by $17 \%$ for recovery prediction and $23 \%$ for discharge prediction when the noise level of the geophysical data increases from 1 to $10 \mathrm{nV} \mathrm{m}^{-2}$.

\section{Discussion}

\subsection{Estimation of parameters in the petrophysical relation}

Parameterizing the groundwater model by assuming a spatially dependent petrophysical relationship between resistivity and hydraulic conductivity makes it possible to use a resistivity voxel model for construction and calibration of a groundwater model. Assuming that the relationship is spatially dependent can account for two challenges: (i) there may be actual changes in the petrophysical relationship within an investigated domain, and (ii) there may be resolution limitations in the estimated resistivity model.

Challenge (i) is likely to be the rule for many environments, especially sedimentary environments, where the formation resistivity is primarily controlled by the pore water resistivity and the clay content. In the case of spatial changes in pore water resistivity and/or the content of various clay mineral content, the discrimination between clay and sands may be less clear in the estimated resistivity values. For largescale groundwater systems, the variation of pore water resistivity (e.g., saline pore water) is expected to vary smoothly, which would be accounted for by the spatially varying petrophysical relationship. However, the procedure only works as applied here if the underlying assumption that clay-rich deposits have lower electrical resistivity than sand deposits is valid.

Challenge (ii) concerns the geophysical model resolution of the true formation resistivity. EM methods are, by nature, more sensitive to deposits of low electrical resistivity than to deposits of high resistivity, and their vertical and horizontal resolutions decrease with depth. This challenge affects the resistivity models estimated in the present synthetic study. Spatially dependent shape factors can take a compensatory role for the resolution issues of the estimated geophysical voxel model. The calibrated shape factors may thus no longer have firm physical meaning because they mainly act as correction parameters for absorbing structural errors of the geophysical model. This is acceptable as long as the resulting hydraulic conductivity values are reasonable. The idea of calibrating the shape factors is related to the concept of compensatory parameters in highly parameterized calibration de- 
scribed by Doherty and Welter (2010) and by Doherty and Christensen (2011).

Finally, Auken et al. (2008) showed that using borehole data as a priori information in the geophysical inversion improves the reconstruction of the model features significantly. Estimation of EM-based resistivity models should therefore, wherever possible, be supported by borehole information to improve the decreasing spatial resolution of the EM methods.

\subsection{Geophysical inversion strategy and data quality}

Inversion of AEM data using a 1-D geophysical model usually applies smoothness constraints in order to regularize the inversion (Auken and Christiansen, 2004; Viezzoli et al., 2008). Traditionally, the regularization includes both lateral and vertical smoothing constraints (Constable et al., 1987) or a few-layer parameterization (Auken et al., 2008). Inversion using the former type of regularization produces smooth images with blurred formation boundaries which can be problematic when it is important to resolve structural connections in a complex geological system. The latter few-layer inversion may also be prone to producing artifacts when used to map such systems. Day-Lewis (2005) and others therefore recognized that regularization used to stabilize the geophysical inversion can lead to artifacts that do not reflect the actual hydrogeological conditions. Thoughtless use of such results to construct groundwater models can have serious ramifications.

For the present case study, the number of vertical transitions is a great challenge for the AEM method due to the principle of high-resistivity equivalence. That is, it is difficult to resolve a high-resistivity layer between two low-resistivity layers because the energy loss, and therefore the sensitivity, is concentrated in the less resistive layers. This will result in layer suppression, because the data sensitivity to the highresistivity layer is low (Christiansen et al., 2006). This effect is present for both the smooth and sharp inversions, but in the sharp inversion the effect is less fuzzy, and features, especially for the fifth layer, could be more clearly reconstructed (Fig. 4). When the sensitivity of the AEM method is too low, the regularization may make information migrate from areas with higher measurement sensitivity (Vignoli et al., 2015). In contrast to the smooth regularization scheme, the sharp regularization method is designed to penalize smooth transitions, which eventually improves the reconstruction of the deeper sand bodies in the present study. Therefore, for the studied case, the sharp regularization methodology should be preferred over smooth regularization, because the sharp constraints correspond better to the actual structures of the reference system (sharp transitions between categorical deposits; Fig. 4). Moreover, because the sharp regularization methodology leads to improved reconstruction of subsurface structures, these models lead to greater accuracy and improvement of most groundwater model predictions (Fig. 9).
The groundwater system considered here is relatively shallow, at least as seen from the perspective of the AEM system used in the demonstration example. This is evident from the transmitted EM signal (Fig. 3). The background noise primarily affects the last time gates $\left(10^{-4}-10^{-3} \mathrm{~s}\right)$ of the lowmoment and, only to a small degree, the high-moment time gates (even for low-quality data). This implies that the resolution of the AEM data is generally high for the upper layers. Therefore, in the present case the upper layers of all the geophysical models (both SHI-smooth and SHI-sharp) are well resolved and to a large extent unaffected by AEM data quality (Fig. 5). However, the deep sand units are difficult to resolve because they give only a weak signature in the AEM data (Figs. 3 and 5). This is particularly true for the poorest AEM data quality cases where the late time gates for the lowmoment measurements are disturbed by background noise.

\section{Summary and conclusion}

We present a workflow for efficient construction and calibration of large-scale groundwater models using a combination of airborne electromagnetic (AEM) data and hydrological data. Other types of data could be integrated as well following the same procedure. First, the AEM data are inverted to form a 3-D geophysical model. Subsequently, the geophysical model is translated into a 3-D model of hydraulic conductivity by using a spatially dependent petrophysical relationship for which the shape parameters are estimated by fitting the groundwater model to hydrological data. The estimated shape factors of the petrophysical relationship primarily work as translators between resistivity and hydraulic conductivity, but they can also compensate for structural defects in the model.

The method is demonstrated for a synthetic case study where the subsurface consists of categorical deposits with different geophysical and hydraulic properties. The AEM data are inverted using both smooth and sharp regularization constraints, resulting in two competitive geophysical models. Furthermore, the influence of the AEM data quality is tested by inverting the sharp geophysical models using data corrupted with four different levels of background noise. The resulting groundwater models are each calibrated on the basis of head and discharge data, and their predictive performance is tested for four types of prediction beyond the calibration base. Predictions of a pumping well's recharge area and groundwater age apply the same stress situation as applied during hydrologic model calibration, while predictions of head and stream discharge are done for a changed stress situation.

It is found that a geophysical model inverted with sharp constraints (SHI-sharp) leads to a more accurate groundwater model than one that is based on a geophysical model inverted with smooth constraints (SHI-smooth). The SHI-sharp model leads to an estimated hydraulic conductivity field of 
greater accuracy and to improvement of most groundwater model predictions. The explanation is that the reference system (like many real hydrogeologic systems) is characterized by sharp transitions between categorical deposits; this is resolved better by the SHI-sharp resistivity model than by the SHI-smooth model.

Finally, it is shown that prediction accuracy improves with AEM data quality for predictions of recharge area, head change, and stream discharge, while the accuracy appears to be unaffected for prediction of groundwater age, which cannot be predicted accurately even with high-quality geophysical data.

\section{Data availability}

All data are synthetic and are available by request to the corresponding author.

Competing interests. The authors declare that they have no conflict of interest.

Acknowledgements. The presented work was supported by HyGEM, integrating geophysics, geology, and hydrology for improved groundwater environmental management, project no. 1115116763. The funding for HyGEM is provided by the Danish Council for Strategic Research. All data are synthetic and are available by request to the corresponding author.

We would like to thank Troels N. Vilhelmsen, Nikolaj Foged, Esben Auken, and Anders V. Christiansen for their participation in discussions and sharing of experiences during the HyGEM project meetings. Finally, we acknowledge the comments from two anonymous reviewers, and editor Bill $\mathrm{Hu}$, whose feedback contributed to improvements of this paper.

Edited by: B. Hu

Reviewed by: two anonymous referees

\section{References}

Abraham, J. D., Cannia, J. C., Bedrosian, P. A., Johnson, M. R., Ball, L. B., and Sibray, S. S.: Airborne Electromagnetic Mapping of the Base of Aquifer in Areas of Western Nebraska, US Geol. Surv. Sci. Investig. Rep. 2011-5219, available at: http://pubs. usgs.gov/sir/2011/5219/ (last access: 4 January 2016), 2012.

Archie, G. E.: The Electrical Resistivity Log as an Aid in Determining Some Reservoir Characteristics, Trans AIME, 146, 54-62, doi:10.2118/942054-G, 1942.

Auken, E., Christiansen, A. V., Jacobsen, L. H., and Sørensen, K. I.: A resolution study of buried valleys using laterally constrained inversion of TEM data, J. Appl. Geophys., 65, 10-20, 2008.

Auken, E. and Christiansen, A. V.: Layered and laterally constrained 2D inversion of resistivity data, Geophysics, 69, 752761, doi:10.1190/1.1759461, 2004.
Auken, E., Christiansen, A. V., Westergaard, H. J., Kirkegaard, C., Foged, N., and Viezzoli, A.: An integrated processing scheme for high-resolution airborne electromagnetic surveys, the SkyTEM system, Explor Geophys., 40, 184-192, doi:10.1071/EG08128, 2009.

Auken, E., Christiansen, A. V., Kirkegaard, C., Fiandaca, G., Schamper, C., Behroozmand, A. A., Binley, A., Nielsen, E., Effers $\varnothing$, F., Christensen, N. B., Sørensen, K., Foged, N., and Vignoli, G.: An overview of a highly versatile forward and stable inverse algorithm for airborne, ground-based and borehole electromagnetic and electric data, Explor Geophys., 46, 223-235, doi:10.1071/EG13097, 2014.

Binley, A., Hubbard, S. S., Huisman, J. A., Revil, A., Robinson, D. A., Singha, K., and Slater, L. D.: The emergence of hydrogeophysics for improved understanding of subsurface processes over multiple scales, Water Resour. Res., 51, 3837-3866, doi:10.1002/2015WR017016, 2015.

Blaschek, R., Hördt, A., and Kemna, A.: A new sensitivitycontrolled focusing regularization scheme for the inversion of induced polarization data based on the minimum gradient support, Geophysics, 73, F45-F54, doi:10.1190/1.2824820, 2008.

Carle, S. F.: T-PROGS: Transition Probability Geostatistical Software, Users Manual, Version 2.1, University of California, Davis, 1999.

Carle, S. F. and Fogg, G. E.: Transition probabilitybased indicator geostatistics, Math. Geol., 28, 453-476, doi:10.1007/BF02083656, 1996.

Certes, C. and De Marsily, G.: Application of the pilot point method to the identification of aquifer transmissivities, Adv. Water Resour., 14, 284-300, doi:10.1016/0309-1708(91)90040-U, 1991.

Chen, J., Hubbard, S., and Rubin, Y.: Estimating the hydraulic conductivity at the south oyster site from geophysical tomographic data using Bayesian Techniques based on the normal linear regression model, Water Resour. Res., 37, 1603-1613, doi:10.1029/2000WR900392, 2001.

Christensen, N. K., Christensen, S., and Ferre, T. P. A.: Testing alternative uses of electromagnetic data to reduce the prediction error of groundwater models, Hydrol. Earth Syst. Sci., 20, 1925-1946, doi:10.5194/hess-20-1925-2016, 2016.

Christensen, S., Rasmussen, K. R., and Moller, K.: Prediction of Regional Ground Water Flow to Streams, Ground Water, 36, 351360, doi:10.1111/j.1745-6584.1998.tb01100.x, 1998.

Christiansen, A. V., Auken, E., and Sørensen, K.: The transient electromagnetic method, in: Groundwater Geophysics - A tool for hydrogeology, edited by: Kirsch, R., first ed., Springer-Verlag, Berlin/Heidelberg, 179-225, 2006.

Clavier, C., Coates, G., and Dumanoir, J.: Theoretical and Experimental Bases for the Dual-Water Model for Interpretation of Shaly Sands, Soc. Pet. Eng. J., 24, 153-168, doi:10.2118/6859PA, 1984.

Constable, S. C., Parker, R. L., and Constable, C. G.: Occam's inversion: A practical algorithm for generating smooth models from electromagnetic sounding data, Geophysics, 52, 289-300, doi:10.1190/1.1442303, 1987.

Cooley, R. L. and Naff, R. L.: U.S. Geological Survey, Techniques of Water-Resources Investigations, Book 3; Chapter B4, Regression Modeling of Ground-Water Flow, 1990.

Day-Lewis, F. D.: Applying petrophysical models to radar travel time and electrical resistivity tomograms: Resolution- 
dependent limitations, J. Geophys. Res., 110, B08206, doi:10.1029/2004JB003569, 2005.

Desbarats, A. J. and Srivastava, R. M.: Geostatistical characterization of groundwater flow parameters in a simulated aquifer, Water Resour. Res., 27, 687-698, doi:10.1029/90WR02705, 1991.

Deutsch, C. V.: A sequential indicator simulation program for categorical variables with point and block data: BlockSIS, Comput. Geosci., 32, 1669-1681, doi:10.1016/j.cageo.2006.03.005, 2006.

Deutsch, C. V. and Journel, A. G.: GSLIB: Geostatistical Software Library and User's Guide: Clayton V., Oxford University Press, Second Edi., Oxford University Press, 1998.

Doherty, J.: Ground Water Model Calibration Using Pilot Points and Regularization, Ground Water, 41, 170-177, doi:10.1111/j.17456584.2003.tb02580.x, 2003.

Doherty, J.: PEST, Model-Independent Parameter Estimation, User Manual, 5th ed, 336 pp., Watermark Numerical Computing, 2010.

Doherty, J. and Christensen, S.: Use of paired simple and complex models to reduce predictive bias and quantify uncertainty, Water Resour. Res., 47, W12534, doi:10.1029/2011WR010763, 2011.

Doherty, J. and Welter, D.: A short exploration of structural noise, Water Resour. Res., 46, W05525, doi:10.1029/2009WR008377, 2010.

Ferré, T., Bentley, L., Binley, A., Linde, N., Kemna, A., Singha, K., Holliger, K., Huisman, J. A., and Minsley, B.: Critical Steps for the Continuing Advancement of Hydrogeophysics, Eos, Trans. Am. Geophys. Union, 90, 200-201, doi:10.1029/2009EO230004, 2009.

Fiandaca, G., Kirkegaard, C., Foged, N., Christiansen, A. V., and Auken, E.: Sharp Spatially-decoupled Inversion of Airborne Electromagnetic Data for Improved Model Integration, First European Airborne Electromagnetics Conference, 26 January 2015.

Fogg, G. E., LaBolle, E. M., and Weissmann, G. S.: Groundwater Vulnerability Assessment: Hydrogeologic Perspective and Example from Salinas Valley, California, American Geophysical Union, Washington, DC, 1999.

Gunnink, J. L. and Siemon, B.: Applying airborne electromagnetics in 3D stochastic geohydrological modelling for determining groundwater protection, Near Surf. Geophys., 13, 45-60, doi:10.3997/1873-0604.2014044, 2015.

Harbaugh, A. W., Banta, E. R., Hill, M. C., and McDonald, M. G.: MODFLOW-2000, The U.S. Geological Survey modular ground-water model: User guide to modularization concepts and the ground-water flow process, US Geological Survey Open-File Report 00-92, 121 pp., 2000.

He, X., Koch, J., Sonnenborg, T. O., Jørgensen, F., Schamper, C., and Refsgaard, J. C.: Transition probability-based stochastic geological modeling using airborne geophysical data and borehole data, Water Resour. Res., 50, 3147-3169, doi:10.1002/2013WR014593, 2014.

Herckenrath, D., Fiandaca, G., Auken, E., and Bauer-Gottwein, P.: Sequential and joint hydrogeophysical inversion using a field-scale groundwater model with ERT and TDEM data, Hydrol. Earth Syst. Sci., 17, 4043-4060, doi:10.5194/hess-17-40432013, 2013.

Hyndman, D. and Tronicke, J.: Hydrogeophysical case studies at the local scale: the saturated zone, in: Hydrogeophysics, edited by: Rubin, Y. and Hubbard, S. S., Springer Netherlands, Dordrecht, 391-412, 2005.
Jørgensen, F., Lykke-Andersen, H., Sandersen, P. B. E., Auken, E., and Nørmark, E.: Geophysical investigations of buried Quaternary valleys in Denmark: an integrated application of transient electromagnetic soundings, reflection seismic surveys and exploratory drillings, J. Appl. Geophys., 53, 215-228, 2003.

Jørgensen, F., Møller, R. R., Nebel, L., Jensen, N.-P., Christiansen, A. V., and Sandersen, P. B. E.: A method for cognitive 3D geological voxel modelling of AEM data, Bull. Eng. Geol. Environ., 72, 421-432, doi:10.1007/s10064-013-0487-2, 2013.

Linde, N., Finsterle, S., and Hubbard, S.: Inversion of tracer test data using tomographic constraints, Water Resour. Res., 42, W04410, doi:10.1029/2004WR003806, 2006.

Marker, P. A., Foged, N., He, X., Christiansen, A. V., Refsgaard, J. C., Auken, E., and Bauer-Gottwein, P.: Performance evaluation of groundwater model hydrostratigraphy from airborne electromagnetic data and lithological borehole logs, Hydrol. Earth Syst. Sci., 19, 3875-3890, doi:10.5194/hess-19-3875-2015, 2015.

Mazáč, O., Kelly, W. E., and Landa, I.: A hydrogeophysical model for relations between electrical and hydraulic properties of aquifers, J. Hydrol., 79, 1-19, 1985.

McNeill, J. D.: Electromagnetic Terrain Conductivity Measurement at Low Induction Numbers, Tech. Note TN-6, 1980.

Menke, W.: Geophysical Data Analysis: Discrete Inverse Theory, Third Edition, MATLAB Edition, Elsevier, Academic Press, Boston, USA, 2012.

Munday, T., Gilfedder, M., Taylor, A. R., Ibrahimi, T., Ley-Cooper, A. Y., Cahill, K., Smith, S., and Costar, A.: The role of airborne geophysics in facilitating long-term outback water solutions to support mining in South Australia, Water, J. Aust. Water. Assoc., 42, 138-141, 2015.

Oldenborger, G. A., Pugin, A. J.-M., and Pullan, S. E.: Airborne time-domain electromagnetics, electrical resistivity and seismic reflection for regional three-dimensional mapping and characterization of the Spiritwood Valley Aquifer, Manitoba, Canada, Near Surf. Geophys., 11, 63-74, doi:10.3997/18730604.2012023, 2013.

Pollock, D. W.: User's Guide for MODPATH/MODPAT-PLOT, Version 3: A particle tracking post-processing package for MODFLOW, the U.S. Geol. Survey finite-difference ground-water flow model, U.S. Geol. Surv. Open-File Rep., 94-464, Version 5, available at: http://water.usgs.gov/nrp/gwsoftware/modpath5/ modpath5.html (last access: 21 Februar 2016), 1994.

Portniaguine, O. and Zhdanov, M. S.: Focusing geophysical inversion images, Geophysics, 64, 874-887, doi:10.1190/1.1444596, 1999.

Purvance, D. T. and Andricevic, R.: On the electrical-hydraulic conductivity correlation in aquifers, Water Resour. Res., 36, 2905 2913, doi:10.1029/2000WR900165, 2000.

Refsgaard, J. C., Christensen, S., Sonnenborg, T. O., Seifert, D., Højberg, A. L., and Troldborg, L.: Review of strategies for handling geological uncertainty in groundwater flow and transport modeling, Adv. Water Resour., 36, 36-50, doi:10.1016/j.advwatres.2011.04.006, 2012.

Revil, A. and Cathles, L. M.: Permeability of shaly sands, Water Resour. Res., 35, 651-662, doi:10.1029/98WR02700, 1999.

Revil, A., Karaoulis, M., Johnson, T., and Kemna, A.: Review: Some low-frequency electrical methods for subsurface characterization and monitoring in hydrogeology, Hydrogeol J., 20, 617658, doi:10.1007/s10040-011-0819-x, 2012. 
Robinson, D. A., Binley, A., Crook, N., Day-Lewis, F. D., Ferré, T. P. A., Grauch, V. J. S., Knight, R., Knoll, M., Lakshmi, V., Miller, R., Nyquist, J., Pellerin, L., Singha, K., and Slater, L.: Advancing process-based watershed hydrological research using near-surface geophysics: a vision for, and review of, electrical and magnetic geophysical methods, Hydrol. Process., 22, 36043635, doi:10.1002/hyp.6963, 2008.

Schamper, C., Jørgensen, F., Auken, E., and Effers $\varnothing$, F.: Assessment of near-surface mapping capabilities by airborne transient electromagnetic data - An extensive comparison to conventional borehole data, Geophysics, 79, B187-B199, doi:10.1190/geo2013-0256.1, 2014.

Seifert, D., Sonnenborg, T. O., Refsgaard, J. C., Højberg, A. L., and Troldborg, L.: Assessment of hydrological model predictive ability given multiple conceptual geological models, Water Resour. Res., 48, W06503, doi:10.1029/2011WR011149, 2012.

Siemon, B., Christiansen, A. V., and Auken, E.: A review of helicopter-borne electromagnetic methods for groundwater exploration, Near Surf. Geophys., 7, 629-646, doi:10.3997/18730604.2009043, 2009.

Slater, L.: Near Surface Electrical Characterization of Hydraulic Conductivity: From Petrophysical Properties to Aquifer Geometries - A Review, Surv. Geophys., 28, 169-197, doi:10.1007/s10712-007-9022-y, 2007.

Strebelle, S.: Conditional Simulation of Complex Geological Structures Using Multiple-Point Statistics, Math. Geol., 34, 1-21, doi:10.1023/A:1014009426274, 2002.
Sørensen, K. I. and Auken, E.: SkyTEM - a new high-resolution helicopter transient electromagnetic system, Explor Geophys., 35, 194-202, 2004.

Thomsen, R., Søndergaard, V. H., and Sørensen, K. I.: Hydrogeological mapping as a basis for establishing site-specific groundwater protection zones in Denmark, Hydrogeol. J., 12, 550-562, doi:10.1007/s10040-004-0345-1, 2004.

Viezzoli, A., Christiansen, A. V., Auken, E., and Sørensen, K.: Quasi-3D modeling of airborne TEM data by spatially constrained inversion, Geophysics, 73, F105-F113, doi:10.1190/1.2895521, 2008.

Vignoli, G., Fiandaca, G., Christiansen, A. V., Kirkegaard, C., and Auken, E.: Sharp spatially constrained inversion with applications to transient electromagnetic data, Geophys. Prospect, 63, 243-255, doi:10.1111/1365-2478.12185, 2015.

Waxman, M. H. and Smits, L. J. M.: Electrical Conductivities in Oil-Bearing Shaly Sands, Soc. Pet. Eng. J., 8, 107-122, doi:10.2118/1863-A, 1968.

Weissmann, G. S. and Fogg, G. E.: Multi-scale alluvial fan heterogeneity modeled with transition probability geostatistics in a sequence stratigraphic framework, J. Hydrol., 226, 48-65, doi:10.1016/S0022-1694(99)00160-2, 1999.

Zhou, H., Gómez-Hernández, J. J., and Li, L.: Inverse methods in hydrogeology: Evolution and recent trends, Adv. Water Resour., 63, 22-37, doi:10.1016/j.advwatres.2013.10.014, 2014. 